\title{
A key performance measures for evaluating cold supply chain performance in farm industry
}

\author{
Shashi Shashi $^{\mathrm{a}^{*}}$ and Rajwinder Singh ${ }^{\mathrm{b}}$
}

${ }^{a}$ Research Scholar, Punjabi University, Patiala, India

${ }^{b}$ Associate Professor, International Management Institute, Bhubaneswar, India

\begin{tabular}{l}
\hline C H R O N I C L E \\
\hline Article history: \\
Received March 25, 2015 \\
Received in revised format June \\
12015 \\
Accepted June 102015 \\
Available online \\
June 112015 \\
\hline Keywords: \\
Cold supply chain \\
Farm industry \\
Measures \\
Execution \\
Importance and effect \\
Measurement instrument
\end{tabular}

\begin{abstract}
A B S T R A C T
The main objective of this study was to develop a set of measures, evaluate their importance and effect in cold supply chain performance. This investigation reviewed previous research works on all the stages of the farm product supply chain. Based on farm product supply chain, 4 measures with 31 metrics were identified and developed to measure the cold supply chain performance. A survey was organized to establish the importance and the effect of identified measures. The 5 point Likert scale questionnaire was distributed among SC academics and practitioners. The observed finding infers that the measurement instrument was substantiating for evaluating cold supply chain performance in farm industry. The new developed metrics will help firms improve the visibility of supply among partners and in better decision making. The investigation was enfolded up through the plan of direction intended for future study.
\end{abstract}

(c) 2015 Growing Science Ltd. All rights reserved.

\section{Introduction}

In today's globalized business, the importance of effective supply chain performance (SCP) is highly increased due to a number of reasons viz. increase in middleman income, customer value orientation, global competition, stakeholder needs, technology and international rules and regulations. For any business firm to tackle these challenges there is a strong need to formulate and execute innovative and effective strategies, that will help in achieving firm's objectives such as customer satisfaction, good will, proper utilization of resources, low cost and high return (Amaeshi et al., 2008; Khatri et al., 2012; Datta, 2013). The supply chain management (SCM) is an integrated process. Therefore, all business partners should try to satisfy all the remarks. To reach an efficient SC, it is highly important to evaluate the performance of the whole SC (Wong \& Wong, 2007). Porter (1985) and Reed and Reed (2010) stated that low cost of product provides a competitive edge to increase the customer values, retention and market share. Handfield and Nichols (1999) supported the same concept to increase the customer values through cost reduction. They suggested that SC focus must be on cost minimization through effective SC planning. Christopher (1998) gave a similar statement that business houses can hold the competitive edge through minimum possible cost that would also satisfy the international rules and

* Corresponding author. Tel: +9876826051, +9882183161

E-mail address: shashikashav37@gmail.com (S. Shashi) 
regulations. The constructing appropriate performance measurement within SC is essential for a better understanding among the partner firms (Doyle, 1994; Fawcett \& Cooper, 1998; Beamon, 1999; Bhagwant \& Sharma, 2007).

The retail industry in India is one of the largest sectors and it contributes the share of around 15\% in total GDP of the country as well as generates employment for 3.4\% pebbles of total population. Traditionally, the firms focus on internal operational performance measurements. It is estimated that total Indian retail business will grow to US\$ 804 billion by 2015 from US\$ 411 billion in 2011 (The Business Monitor International India Retail Report). The farm product retailing is all about selling horticulture products, livestock products and processed farm products. India has shown a good growth rate in the retail sector because of the large population with increasing in middle class income, high demand for luxury goods and changed consumer behavior.

Traditionally, the firms focus on internal operational performance measurements. But with the advent of new technology and high pressure of competition, the traditional SC has extended. In today's business world, firms not only need to measure operational process but also supplier evaluation, distributor evaluation, machine evaluation, customer satisfaction, retention rate and SC flexibilities evaluation etc. are equally important. Hence, firms have to move toward integrated planning and new methods for developing the structure of SCM. SCP measurement has been recognized as a key source towards an effectual and well-organized SCM. The coordination among integrated players in the SC is a solution to its successful implementation (Lee, 2000; Shah \& Singh, 2001; Turker \& Altuntas, 2014, Rani et al., 2015). Similarly, the issue of measurement of integrated SCP is supported by other researchers (Handfield \& Nichols, 1999; Lambert \& Pohlen, 2001; Chan et al., 2003; Gunasekaran \& Kobu, 2007). Bond (1999) stated that performance measurement is an information generated tool that suggests whether the firm should go forward with present strategies or need to alter these. Mentzer et al. (2007); Brettel et al. (2012) and Singh et al. (2014) emphasized that many firms had wound up their business due to unreliable and irregular measurement of their SCP. If the firms are not able to measure SCP, then they are not able to control, manage and improve it. Thus, to overcome this problem, the development and evaluation of measures are highly important.

Generally, this study starts with an explanation of cold supply chain performance (CSCP). Further, it goes ahead to explain a conceptual framework for the measurement of CSCP in the farm industry. During this, a set of metrics is established for the measurement of CSCP. These metrics are selected on the basis of literature review and after the discussion with farm product SC experts. A survey was conducted to measure the importance and effect of measures on the farm product industry. Further, this study ended with a conclusion and a direction for future research.

\section{Conceptual background}

In this part, concept of cold supply chain has been discussed. Further, the previous literature on SC performance measurement is used to describe its importance in business. In general terms, it involves the previous investigations of various researchers in the context of SCP measurement to highlight the need for CSCP measurement.

During 2013-14, India has produced 280 million MT of horticulture products, 30 million MT of meat, poultry, fish \& butter, 137 million liters of milk and 69731 million pieces of eggs. But the problem of wastage is yet not mitigated. Large share, approximately $35 \%-40 \%$ of total yield of farm products have been getting wasted annually due to poor SCP (Shashi \& Singh, 2015). Only some of the key components of the farm product waste reduction is to use of modern system of cold chain logistics. The term cold supply chain is much similar than other SC products. But a major difference between both is the role of environmental conditions such as temperature, humidity, light, etc. Cold supply products is perishable in nature since they need special temperature monitoring treatments during warehousing and 
movement of farm products. The cold supply chain includes the SC of the farm as well as pharmaceutical industry, but in this study we focused on farm industry. Many SC scholars have used different terms to express the cold supply chain. Viswanadham, (2005) defined it as a temperature monitoring SC. It has been explained as a farm product waste reduction SC (Maheshwar \& Chanakwa, 2006; Athapol \& Ahmed, 2008; Aung, et al., 2013). Bogataj and Vodopivec, (2004) called it as a cold logistic chain. Further, Lin et al. (2014) and Fatehpuria (2013) described its quality and quantity control SC. NCCD went ahead and defined that cold supply chain is a combination of goods, services and technology associated with cold chain operations and list is continued. But here, all these definitions are talking about the same concept, i.e., concept of temperature control. Hence, the cold supply chain is special temperature treatment supply chain for the farm products like fruits and vegetables, dairy product, sea food and eggs, etc. (Shashi \& Singh, 2015). It enhances the shelf life of farm products with collective efforts to reduce the amount of wastage with proper temperature controlling (Guritno et al., 2015) during storage, movement and retail. The purposed cold supply chain process is presented in Fig. 1.

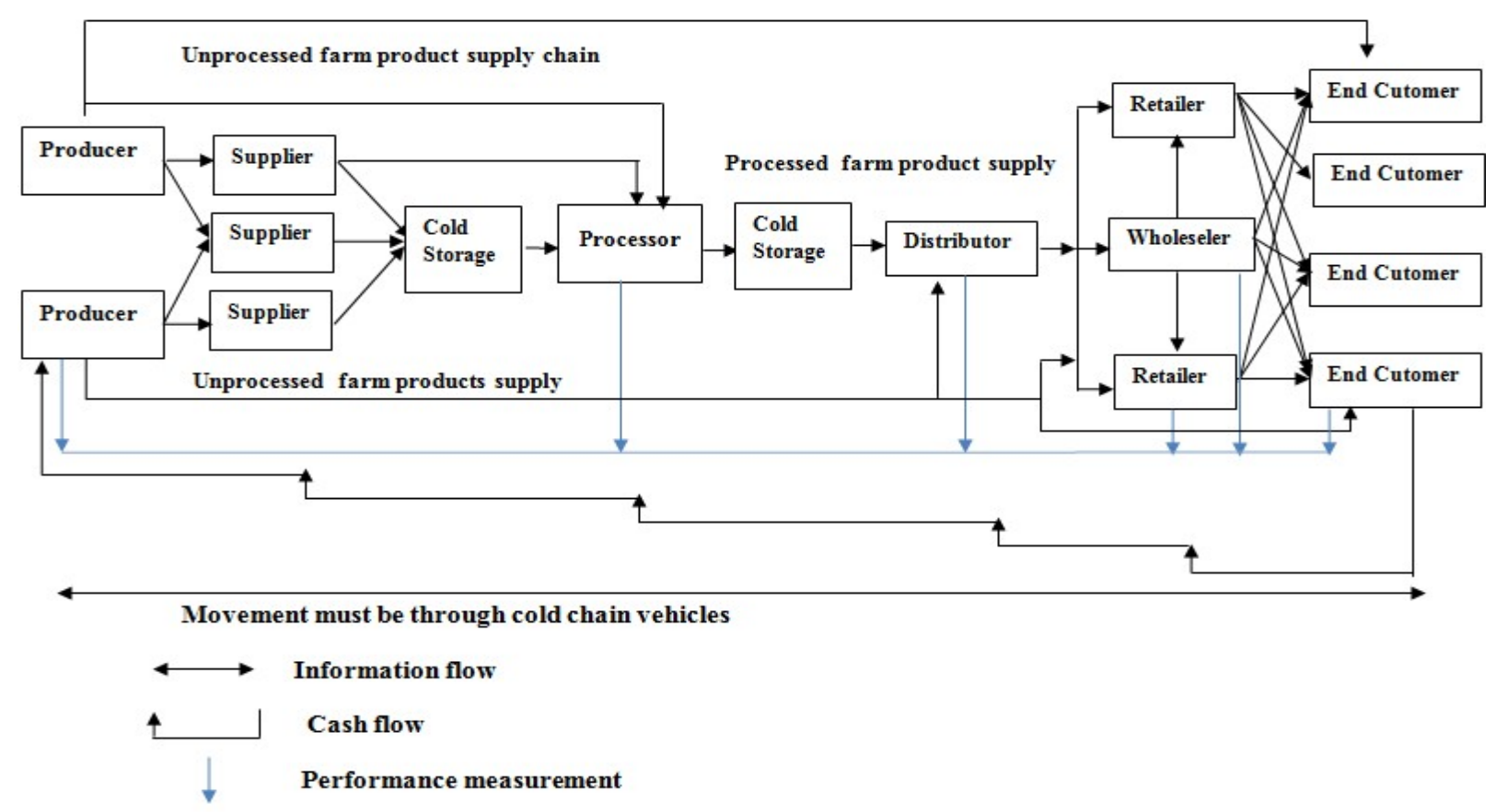

Fig. 1. Cold supply chain process

Maheshwar and Chanakwa (2006) gave a statement about the amount of farm products that shrinkage can be minimized with the collective efforts of producers, suppliers, processors, distributor and retailers. Bruckner et al. (2013) and Dewi (2015) highlighted that all farm products always have a short life span. Similarly, different types of products need different ranges of temperatures. Athapol and Ahmed (2008) stated that the share of this wastage can be minimized through high level of farm product processing during SC loop. The absences of information, material, resources in any stage will also hinder the benefits of the next stage. Farm products are daily consumption products. Due to the high populated world, the demand of fresh and hygienic products is increasing regularly (Ren \& An, 2010). To meet this uncontrollable demand, firms need to control and manage SCP measures. With the development of cold supply chain, it plays a role of a game changer for all SC players to enhance their competence between competitors. Likely, it increases the worth of customer purchase (Zhao, 2010). Improving SCP is one of the critical issues of business to attain sustained competitive benefits (Holweg et al., 2005; Athapol \& Ahmed, 2008; Estampe et al. (2013). To manage farm product SC is a difficult job due to different interest of involved parties (Qin, 2015). Hence, there are a number of reasons that 
create a need to measure CSCP in the farm industry. Many researchers have defined performance measurement in their own views are given in Table 1 as follows,

\section{Table 1}

Performance measurement

\begin{tabular}{ll}
\hline Researchers & Views \\
\hline Mentezer and Konard, 1991 & Effectiveness and efficiency of accomplishing a particular task \\
Neely et al., 1995 & A method of quantifying the efficiency and competence of actions \\
Bond, 1999 & An information generation tool for qualitative SC decision making \\
\hline Slack et al., 2001 & A process of evaluating quality, dependability, flexibility, speed and cost \\
\hline Karrer, 2003 & Balancing SC behavior and orientation through firm evaluation \\
Gunasekaran et al., 2004 & System of evaluating plan, execution, output and controlling activities \\
\hline Lonman et al., 2004 & Co-ordination effort that explains current metrics to recognize shortcomings \\
Park et al., 2005 & $\begin{array}{l}\text { Course of determining future SC directions and activities by measuring present practice’s } \\
\text { effect of SC }\end{array}$ \\
\hline Charan et al., 2008 & Course of identifying how well the present SC system is working \\
Elgazzar et al., 2012 & Tool of identifying the gaps between the plan and its execution \\
\hline Estampe et al., 2013 & Composition of several actors cooperating to achieve defined objectives \\
Fan et al., 2013 & Evaluation technique of firms systems and technology for SC improvement \\
Shafaee et al., 2014 & A capability of firm for evaluating actions and activities in a significant manner \\
\hline
\end{tabular}

Wong and Wong (2007) supported that the effective measurement of SCP is highly important. Consequently, to develop CSCP measurement, metrics are very essentials to control, manage and for paramount performance (Bogataj \& Vodopivec 2004; Maheshwar \& Chanakwa, 2006; Athapol \& Ahmed, 2008; Olugu et al., 2011, Aung et al., 2013). Singh et al. (2013) suggested that the performance measurement model provides a vital knowledge about (1) where the firm stands? (2) To what extent, the available resources are utilized? (3) What are the key areas where firms have to give more attention? (4) Is there a need to modify the current strategies or not? In the past, some measures were less important, but now it is extremely important to evaluate each and every measure that has affected SCP. According to Gunasekaran et al. (2004) SCP measurement should be able to capture the real firm performance. In addition, the measurements of SCP should be minimum manipulated and easily understandable by each and every SC partner (Schroeder et al. 1986; Lee \& Billington 1992; Shabani et al. 2012; Kumar et al., 2015). Gunasekaran et al. (2004) highlighted that it is necessary that performance measurement objectives should represent firm objectives. It will help firms to strengthen their SCP.

Many researchers demonstrated the need of cold supply chain performance measurement (McKinnon, 1999; English \& Castelluccia, 2006; James \& James, 2010; Parraga et al., 2011; Shabani et al., 2012; Aung \& Chang, 2014) but there is still no study available on cold supply chain performance of farm products. Therefore an attempt has made to evaluate the cold supply chain performance.

\section{Performance measurements and metrics for CSCP in the farm product industry}

In this section, the literature on performance measurements and metrics in SCM is reviewed. The metrics and measures are discussed in the context of the farm product SC activities:

\subsection{Evaluation of customer services perspective}

This involves concern on customers' satisfaction view with respect to farm product SC. In current scenario of business, the major business objective is to satisfy present customers as well as to attract new customers for increasing market share. Theyel, (2006) and Najmi et al. (2013) believed that effective evaluation of a customer satisfaction measure leads firms towards paying more attention towards customer orientation rather than product orientation. Under this measure, the considered metric are given below. 


\subsubsection{Product quality (PQ)}

This is a parameter of measuring the standard and capability (Pearson \& Olhager, 2002) of product to fulfill the customer's expectations. This attribute varies from product to product. Generally, the postharvest quality losses are very common in farm product SC. It has high impact on post purchasing behavior of customers. Many researchers highlighted that it plays an important role in CSCP (Chan et al., 2013; Aramyan et al., 2007).

\subsubsection{Product personality (PP)}

This is a glaring measure that has high influence on farm product buying decisions (Desmet et al., 2008; Bruckner et al., 2013). The farm product personality covers hygienic, size, shape, labeling and packaging. Many investigations have acknowledged its consequence to boost CSCP. It is assumed that the farm product's personality ensures the level of customer's satisfaction (Bogataj \& Vodopivec, 2004; Viswanandham, 2005; Zhu et al., 2007).

\subsubsection{Product variety $(P V)$}

This metric covers the range of product in different categories (size, design, color, taste, price, quality and weight). The firm with more product variety will have more customers, sale and profits (Mapes et al., 1997). High variety of processed farm product provides an advantage to firms to capture an untouched market through over all care of customer's different needs. According to Singh et al. (2013) it is a key measure to evaluate the firm SCP.

\subsubsection{Cold chain (CC)}

This metrics deals with the machineries installed in warehouses and supply vehicles. Shabani et al. (2013) expressed that the higher use of cold chain facilities such as refrigerator, containers, etc., the lower spoilage rate of farm products. Without the cold chain, it is impossible to control the quality and quantity losses of farm products. Lan et al. (2014) stated that cold chain plays an important role to store supplies and enhance the shelf life of farm product. It also gave more satisfaction to buyer by providing off seasonal availability of farm products.

\subsubsection{Fill rate $(F R)$}

It aimed to evaluate the proportion of customer's orders that are filled in the first shipment. Many researchers consider the fill rate as an important metric for evaluating SCP. This metric has high implication on measuring transportation efficiency. On Time Delivery, Stock Keeping Units, Case fill rate and order line value are some measures of total fill rate.

\subsubsection{Customer's product return rate (CPRR)}

Under this metric, the percentage of orders returned from buyer to seller are evaluated. Singh et al. (2013) called it the returnable products are of inferior quality. Park et al. (2005) highlighted that firm should minimize these returns through quality management and returned products should be replaced as soon as possible. Otherwise, it will waste firm time and resources. Lambert and Terrance (2001) supported that customer's product return rate is a key metric to measure SCP.

\subsubsection{Customer retention rate (CRR)}

This takes into explanation of percentage of retained customers. If any business houses want to be successful, there is a need to have a high rate of customer retention. This metric ensures that the value 
addition and customer care are highly important to maximize the rate of customer retention. The retained customers make a flow of regular selling of farm products for the firm. It is believed that this indicator has high impact on farm product CSCP.

\subsubsection{Customer query time (CQT)}

This is a time taken by firm to resolve and respond customer's queries with necessary information (Gunasekaran et al., 2004). Speedy and accurate responses to customer's queries are very necessary for enhancing the level of customer's satisfaction (Zorzini \& Stevenson, 2012). Najmi et al. (2013) called it a customer problem solving time. Thus, this is a crucial metric for CSCP.

\subsection{Evaluation of internal supply chain practices}

This measure evaluates the overall internal supply chain performance to make sure that the desired performances are achieved. In this measure, there are some metrics, which can be employed. Park et al. (2005) and Bhagwant and Sharma (2007) considered this measure as a critical business success factor.

\subsubsection{Evaluation of supplier performance (ESP)}

Under this indicator, the overall potential and efforts of suppliers are evaluated. The process considers supplier's performances in the context of SC efficiency, cost, quality, responsiveness to reduce cost, risk and high efficiency (Najmi et al., 2013). The potential suppliers will help firms in adding value in entire CSCP.

\subsubsection{Evaluation of shrinkage (ES)}

This aimed to evaluate the amount of wastage of raw material and finished products at supplier, processor, distributor and retail ends. The farm products get spoiled easily due to their temperature sensitivity. Firms can reduce this percentage of shrinkage with the use of cold storage and refrigerators during warehousing and movement of products. Many researchers demonstrated the evaluation of shrinkage is crucial metric for measuring CSCP. Chia et al. (2009) and Olugu et al. (2011) called it SC losses and emphasis an important metric for the measurement of SCP.

\subsubsection{Evaluation of equipment performance (EQP)}

This metric evaluates the performance of equipment and machinery by making their time to time output comparison. This comparison can be in the form of equipment to equipment or comparing past and present performance from the same equipment. This indicator is crucial for estimating the depreciated performance of equipment and highlights the need of new one.

\subsubsection{Employee evaluation (EE)}

This includes the evaluation of all outputs of employees. CSCP involves numbers of permanent and part-time employee for performing numerous SC tasks. Noone (2008) and Hunter (2006) called this after training evaluation, while Olugu et al. (2011) expressed it as overall performance evaluation like working efficiency, devotion and total output. Employee evaluation directs firms to make qualitative working policies for attaining reliable performance. Thus, this indicator is regarded as important CSCP metric. 


\subsubsection{Evaluation of customer satisfaction (ECS)}

This metric has high impact on improvement of business SCP. Customer satisfaction is defined as to what extent, the consumed product and service fulfilled the customers' expectations in the form of quality, quantity, taste and price. The customer satisfaction can be calculated through customer's feedback and repurchasing of the same products or services. In the market, competitors compete for customers. Without a satisfied consumer, the cold supply chain plans cannot be deemed successful. Therefore, customer satisfaction evaluation is necessary for determining the percentage of satisfied customers. Many researchers supported that evaluation of customer satisfaction is a key performance metric to evaluate the SCP.

\subsubsection{Evaluation of stakeholder satisfaction (ESS)}

If a firm wants to tackle the global completion and increase market share, then there is a need to evaluate the satisfaction level of firm's stakeholders. The stakeholder satisfaction should be top priority (Park et al., 2005 \& Singh et al. 2013). Neely et al. (2002) defined it as an entire stakeholder satisfaction evaluation. It is believed that the higher stakeholder satisfaction, the higher business returns. Hence, it is an important CSCP measurement metric.

\subsubsection{Demand flexibility (DF)}

This metric evaluates shifted the time of consumption of the product or service In other words, an extent of change in the order due to shift in customers' demands. It has high impact on maintaining the proper balance between demand, supply process and price formation decisions. The SC should be able to make changes in customers' orders without much effect on the system. Singh et al. (2013) termed it as the effectiveness of scheduling.

\subsubsection{Production flexibility (PF)}

This metric is a business strategy that responds to make changes in product that is to be produced (Beamon, 1999; Jile et al., 2007). This flexibility reduces the amount of wastage, reduced downtime and helps in better control over quality. It strengthens the CSCP with fulfilling the particular customer's requirements by processing the raw farm products into new products.

\subsubsection{Supply chain delivery flexibility (SCDF)}

This is an important measure to maintain long-lasting relationship (Novich 1990; Coltman, 2012). It is an ability of suppliers, firm, distributors and retailers to deliver a particular order at demandable place and schedule. The flexibility in delivery system provides a lane for regular service improvement (Chan et al., 2003; Gunasekaran et al., 2004; Xu et al., 2009). Therefore, it is treated as an important indicator that has effects on SCP.

\subsection{Evaluation of financial practices}

This is the overall financial performance of the firm during the SC process. It is believed that financial practices are the indicators of organizational profitability. Neely and Bourne (2002), Chia et al. (2009) and Shafiee et al. (2014) considered it an important measure. Olugu et al. (2011) also supported this fact. Under this measure the considered metrics are given below: 


\subsubsection{Inventory cost (IC)}

This metric covers the cost associated with inventory procurement, storage and maintenances on certain time period. Varma et al. (2008) demonstrated it as a proportion of inventory value on an annual basis. Farm product SC needs a variety of inventory management to satisfy the customer's orders. Ramdas and Speakman (2000) emphasized that inventory cost metric has high impact on final product price. Many researchers highlighted the inventory cost is one of the major metrics to evaluate effectiveness of CSCP.

\subsubsection{Processing cost (PC)}

Under this metric, the cost associated with conversion of farm raw material into processed products is measured. It involves draining cost, machinery depreciation rate, labor payments and energy consumption bills, etc. It is believed that processing cost has high influence on product's retail price.

\subsubsection{Value addition cost (VAC)}

Under this indicator, the money invested of value addition during SC is considered. Bovea and Vidal (2004) called it a cost for the worth of customer money; Chowdhury et al. (2014) supported it by saying that firms should focus on high value addition to tackle the market competition. Hence, it is extremely important to measure the cost of value addition in farm product.

\subsubsection{Information sharing cost (ISC)}

This includes the cost of flow of required information from one end to others. Bhagwant and Sharma (2007) called it information moving cost, where Gunasekaran et al. (2001) considered it information handling expenses. This cost also includes the radio frequency identification (RDIF) cost for data exchange through electronic tags. Olugu et al. (2011) highlighted that the SC partners should communicate accurate information by using modern technology.

\subsubsection{Distribution cost (DC)}

This cost is associated with expenditure on movement of products from production point to retail point. To attain cost effective competitive advantage, the understanding of sum of distribution cost is very essential. Thomas and Griffin (1996) supported that the distribution cost covers more than half of total logistic cost and essential SC key metric (Gunasekaran et al., 2004).

\subsubsection{Return on investment (ROI)}

This is aimed to measure the revenue generated from a particular investment. In other words, an estimation of recouping on what firm invests. It works as a guide for better commerce decision making. With the regular evaluation of this measure, organization can tabs their financial performance. Bigliardi and Bottani (2010) considered that measurement of return on investment should be a top priority for business organizations. Viswanandham (2005) highlights it as a crucial indicator for measuring CSCP.

\subsubsection{Sale revenue $(S R)$}

This involves the total collection of money after selling products or services. It helps the managers in analyzing the financial statement. Shaiee et al. (2014) emphasized that it provides actionable information about firm value. Najmi et al. (2013) called it a total revenue generation. Park et al. (2005) believed that it has high impact on marketing investment decisions and a crucial metric to measure SCP. 


\subsubsection{Sale profit (SP)}

This measures the total sale profit earning by subtracting the expenditure of doing business. Singh et al. (2013) called it a total gain over the items sold. Lai et al. (2002); Murthy, (2011); Singh et al. (2013) and Shaiee et al. (2014) pointed out that the evaluation of sale profit is as important as sales revenue. Neely et al. (2002) also highlighted it as a crucial metric of SCP.

\subsection{Supply chain responsiveness}

Balancing SC responsiveness is an important business subject. This implies that SC responsiveness affects the SC reliability and effectiveness. Beamon (1999) and Olugu et al. (2011) demonstrated that supply chain responsiveness is a key measure to evaluate SCP. Singh et al. (2013) highlighted that responsiveness has a high effect on formulating SC plans. Therefore, the measurement of its importance and effect on SCP is necessary.

\subsubsection{Level of Supplier commitment (LSC)}

This metric explains the degree of devotion of supplier to fulfill the firm needs. This is taken as one of the most key measures to evaluate the farm product SCP. The business uncertainties are the major concern that generates the need for high level of supplier's commitment. In addition, it leads towards healthy business deals. Olugu et al. (2011) believed this to be a very important key metric.

\subsubsection{Supplier lead time (SLT)}

This is the time between receiving an order and final delivery of components, raw material and by the supplier to firm. Bozer and McGinnis (1992), Arntzen et al. (1995); Beamon (1999) and Chan et al. (2003) considered this a crucial measure to evaluate the SCP.

\subsubsection{Processor leads time (PLT)}

This measures the time between order receiving up and the processing of the last unit. Beamon (1999) highlighted that it is a firm responsiveness of how much time they will take to fulfill a particular order?

\subsubsection{Distributor lead time (DLT)}

This measures the time taken by distributors to supply the farm products to retailers for selling. It affects the retailer's available selling time to sell farm commodities (Chan et al., 2003; Bhagwat \& Sharma, 2007). In the words of Stewart (1995) an increase in distributor delivery performance is only possible through a minimizing the distributor's lead time. This clearly suggests the distributor lead time is a crucial metric for measuring CSCP.

\subsubsection{Supply chain cycle time (SCCT)}

This is a total time of farm product SC that begins with the producers and ends with final customers. This cycle time includes the supply of components, raw material and finished products. Many researchers find that this metric has a high effect on firm SCP (Beamon, 1999; Gunasekaran et al., 2001; Cox \& Chicksand, 2005; Viswanandham, 2005; Singh et al., 2013).

\subsubsection{Shipping errors (SE)}

These are the mistakes that occur in the delivery system. These are in the form of order delivery on wrong address, date, time, quality and quantity. The order should be delivered according to agreed 
invoice. By comparing the ordered invoice with final delivery, the shipping errors can be calculated. These errors should minimize as much as possible otherwise the customers will switch to other brands.

\section{Research methodology}

The framework proposed by Olugu et al. (2012) was used for conducting a survey to measure CSCP. A three page questionnaire was formulated for calculating the set of performance measures. The questionnaire was divided into the two parts. The first part was about the details of sample respondents, while the second part was about the importance and effect of performance measures. The content validity of the questionnaire was tested through SC expert's views. We requested them to review the measures to make sure that measures represent CSCP of farm products. On the behalf of experts' views, the errors were eliminated.

The importance and effect of a set of measures were rated on a 5 point Likert scale. The importance was rated as, 1- Little, 2- Some, 3- Average, 4-High and 5-Extreme. Similarly, the effect was rated at 1- Poor, 2-Fair, 3-Good, 4- Very Good and 5-Excellent.

Further, the pilot survey was conducted to ensure and refine the developed instrument. We took a sample size of 21 respondents for this pilot study. We also requested the respondents to give suggestions for the superior modification of the instrument. The valid collected data was analyzed with the help of SPSS. The obtained results of the pilot study fulfilled the entire requirement for conducting the final survey.

After this, the final questionnaire was distributed through electronic mail and post for data collection. A total of 183 questionnaires were mailed to farm products SC practitioners and academicians. All the targeted respondents were engaged in CSCP of farm product within the India. Further, the MannWhitney U-test was used to test the null hypothesis (Ho).

\section{Results and discussion}

In order to measure the efficiency of farm product SC, the questionnaires were distributed for data collection. The process took 39 days for receiving final data. The total 183 were mailed, but only 64 questionnaires were returned. The obtained data fulfilled Gunasekaran et al. (2004) data adequate rate. After receiving the responses, it was found that 6 of them were not of any use because of missing data values and incompleteness. Finally, 58 valid data set questionnaires were used for this study. We first calculated the mean of all measures' metrics to evaluate their importance and effect in CSCP. The obtained results are summarized through figures for better data representation in Figs. 2-10.

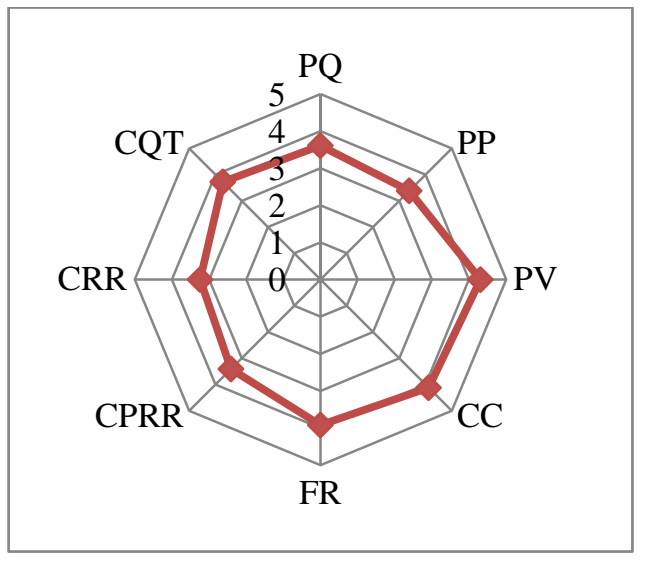

Fig. 2 Customer services perspective

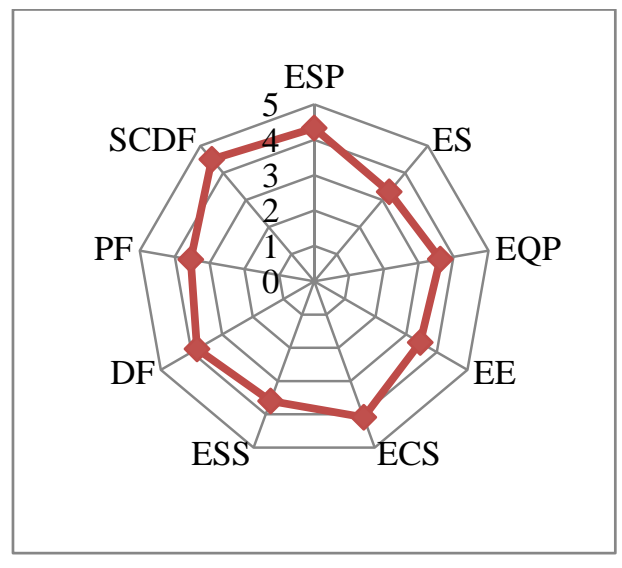

Fig. 3 Internal supply chain practices 
Here, the first measure is customer services perspective. Fig. 2 shows that product variety (PV)) had the maximum highest value of 4.31 . This value implied an $86.2 \%$ importance of this metric. Further, this metric was followed by cold chain (CC) - 4.12, fill rate (FR) - 3.96, customer query time (CQT) 3.72, product quality (PQ) - 3.61, customer product return rate (CPRR) - 3.41, product personality (PP) - 3.38, and customer retention rate (CRR)- 3.24. These indicated an importance percentage of 82.4\%, $79.2 \%, 74.4 \%, 72.2,68.2 \%$ and 67.6 , respectively.

The internal supply chain practice measure's metrics were presented in Fig. 3. Here, the supply chain delivery flexibility (SCDF) had the highest value of 4.50 that explains $90 \%$ its importance. This metric followed by evaluation of supplier performance (ESP) - 4.33, evaluation of customer satisfaction (ECS) - 4.09, demand flexibility (DF) - 3.82, evaluation of equipment performance (EQP) - 3.62, evaluation of stakeholder satisfaction (ESS) - 3.60, production flexibility (PF) - 3.54, employee evaluation (EE) 3.46 and evaluation of shrinkage (ES) -3.30. This explained 86.6\%, 81.8\%, 76.4\%, 72.4\%, 72\%, $70.8 \%, 69.2 \%$, and $66 \%$, respectively.

As earlier discussed, the next measure was evaluation of financial practices. The metrics of this measure were summarized in Fig. 4. It can be seen that inventory cost (IC) had the highest mean score of 4.23, which indicates $84.6 \%$ importance rate. This was followed by information sharing cost (ISC) - 4.20, processing cost (PC) - 4.10, sale profit (SP) - 3.97, return on investment (ROI) - 3.96, sale revenue (3.88), distribution cost (DC) - 3.58 and value addition cost (VDC) - 3.50, with 84\%, 82\%, 79.4, 79.2\%, 77.6\%, 71.6\% importance percentage, respectively.

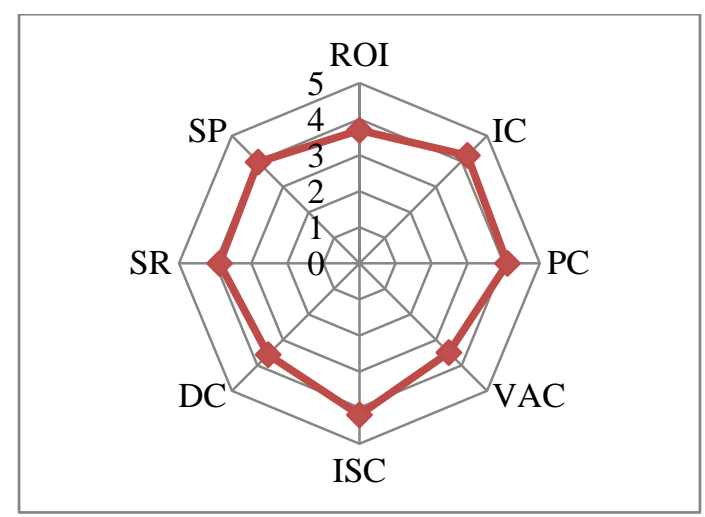

Fig. 4 Financial practices

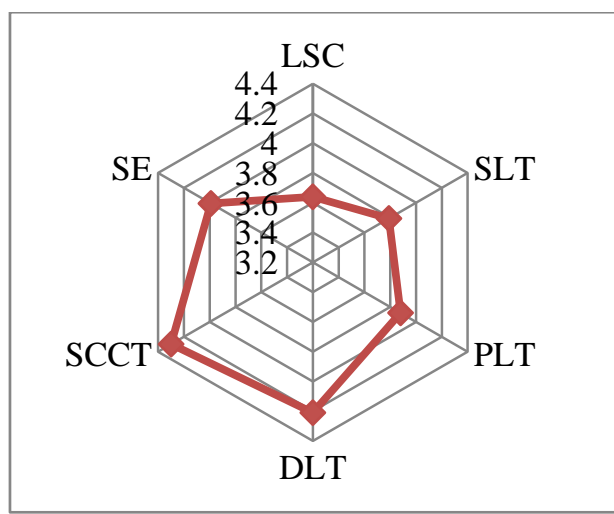

Fig. 5. Supply chain responsiveness

The importance of supply chain responsiveness was presented in Fig. 5, the supply chain cycle time (SCCT) had the highest mean score of 4.30 that implied 86\% importance percentage. This indicator was followed by distributor lead time (DLT) - 4.21, shipping errors (SE) - 3.99, manufacture lead time (PLT) - 3.88, supplier lead time (SLT) - 3.79 and level of supplier commitments (LSC) - 3.64. These represent $84.2 \%, 79.8 \%, 77.6 \%, 75.8 \%$ and $72.8 \%$ importance percentage, respectively.

In the expression of affect, the outcomes of all measures are summarized in Fig. 6-9. Fig. 6 expresses the effect of customer services perspective that the product quality (PQ) had the highest effect of 4.13. This effect was followed by cold chain (CC) - 4.02, customer query time (CQT) - 3.94, product variety (PV) - 3.88, customer retention rate, fill rate (FR) - 3.86, (CRR) - 3.64, product personality (PP) - 3.54 and customer product return rate (CPRR) - 3.50. 


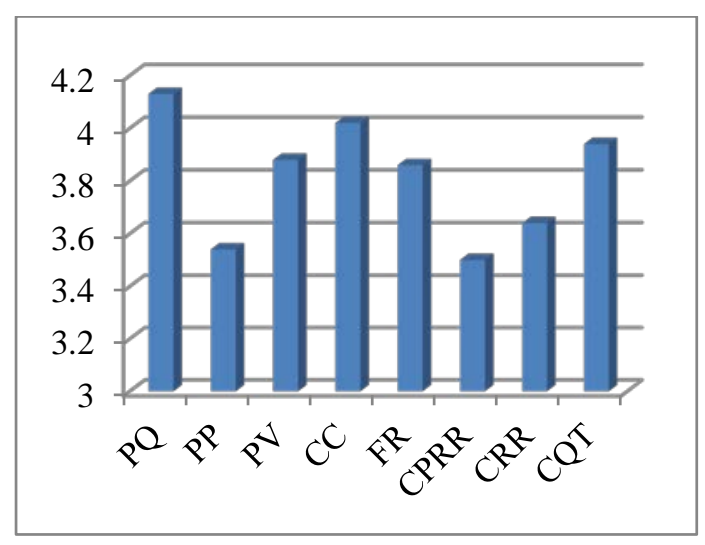

Fig. 6. Customer services perspective

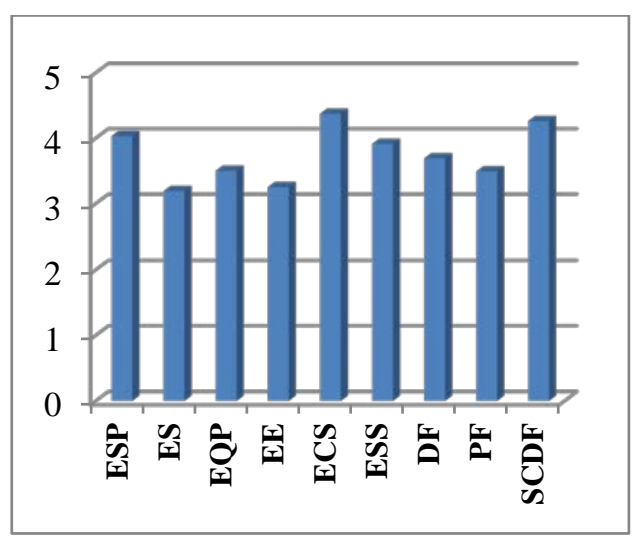

Fig. 7. Internal supply chain practices

The result of internal supply chain practice measure's metrics effects was presented in Fig. 7. It can be seen that evaluation of customer satisfaction (ECS) had the highest effect score of 4.37. This effect was followed by supply chain delivery flexibility (SCDF) - 4.26, evaluation of supplier performance (ESP) - 4.03, evaluation of stakeholder satisfaction (ESS) - 3.91, demand flexibility (DF) - 3.69, evaluation of equipment performance (EQP) - 3.50, production flexibility (PF) - 3.49, employee evaluation (EE) - 3.25 and evaluation of shrinkage (ES) - 3.19.

The effects of financial measure were presented in Fig. 8. It expressed, processing cost (PC) had the highest effect of 4.24. This was followed by inventory cost (IC) - 4.18, sale revenue (SR) - 4.14, information sharing cost (ISC) - 4.09, sale profit (SP) - 4.02, return on investment (ROI) - 3.84, distribution cost (DC) - 3.76 and value addition cost (VAC) - 3.69.

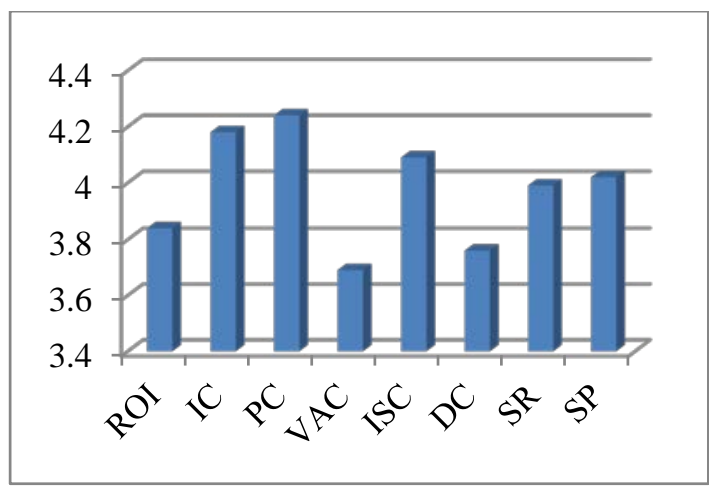

Fig. 8. Financial practices

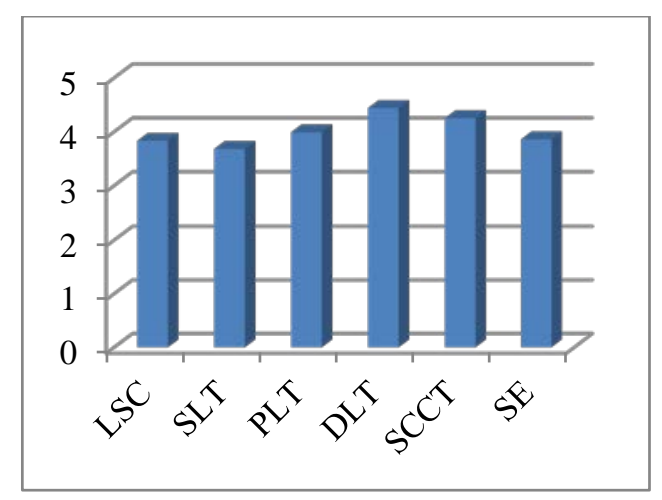

Fig. 9. Supply chain responsiveness

The effects of SC responsiveness were presented in Fig. 9. It can be seen that distributor lead time (DLT) had the highest effect of 4.44. This was followed by supply chain cycle time (SCCT) - 4.25, manufacturer lead time (PLT) - 3.99, level of supplier commitment (LSC) - 3.83, shipping errors (SE) - 3.86 and supplier lead time (SLT) - 3.68.

After this was performed to evaluate the difference between the mean score of measures' importance and effect. This statistical analysis was conducted with the help of SPPS. Basically, Mann-Whitney Utest is non-parametric test and used to test the null hypothesis which contained two data sample set from the same population. The main intention behind this was to evaluate the difference between the mean scores of importance and effect. Here, the Ho = there is not a statistical difference between measures' importance and effect. Therefore the data set was compared by using SPSS. The findings inferred that there was no significant difference between measures' importance and effect. Because none of the $P$ value is less than 0.05. But, within the customer service perspective measure the value of product quality (PQ) importance mean (3.61) and effect mean (4.13) had difference. Similarly, in the 
same measure the product variety (PV) had an importance and effect mean difference of (4.31) and (3.88) respectively. Might be, the reason behind this was that the respondents thought the unprocessed farm products have a high market share without much variety in the same product. But the total importance and effect mean of this measure had no high difference and obtained $\mathrm{P}$ value is also less than 0.05 . The cold chain (CC) importance and effect had also high score.

\section{Table 2}

The results of testing hypotheses

\begin{tabular}{lccccc}
\hline Measures & P-value & $\begin{array}{c}\text { Total importance } \\
\text { mean Score }\end{array}$ & $\begin{array}{c}\text { Importance } \\
\text { mean score }\end{array}$ & $\begin{array}{c}\text { Total effect of } \\
\text { mean score }\end{array}$ & $\begin{array}{c}\text { Effect mean } \\
\text { score }\end{array}$ \\
\hline Customer services perspective & 0.330 & 29.75 & 3.71 & 30.51 & 3.81 \\
Internal supply chain practices & 0.612 & 34.26 & 3.90 & 33.69 & 3.74 \\
Financial practices & 0.435 & 21.15 & 3.89 & 31.81 & 3.97 \\
SC responsiveness & 0.735 & 23.81 & 3.96 & 24.05 & 4.00 \\
\hline
\end{tabular}

This expressed that cold chain helps in maintaining the quality and quantity of farm product and deliver high satisfaction to customers through fresh product. Gunasekaran et al. (2014); Olugu et al. (2011); Singh et al. (2013); Shafiee et al. (2014) supported customer services perspective measure should be core for SCP evaluation. The P values of all measures were presented in Table 1 and graphical presentation of total importance and effect means scores are presented in Fig. 10.

For the internal supply chain practices, all the metrics had almost the same importance and effect means. The $\mathrm{P}$ value for this measure was 0.612 . This shows that this measure's importance and effect had no significant difference. It was calculated that the measure had averaged importance (3.80) that effect (3.74) score. This is almost high importance and very good effect, according to measurement scale. Lai et al. (2002) and Najmi et al. (2013) considered this as a very crucial measure to evaluate SCP.

On financial practices, there is no difference between the importance and effect means score. The measure had importance (3.89) and effect (3.97) score mean. This can be considered as high importance and very good effect, according to measurement scale. Similarly, inventory cost had highest importance mean and processing cost had a highest effect mean score. The P value of this measure was 0.435 that indicated no significant difference. The measured result implies that the proper evaluation of cost associated with business should be properly evaluated before making any investment. Stewart (1995); Bhagwant and Sharma (2007) and Jabbour et al. (2010) emphasized that SC performance evaluation cannot be accessed without measuring financial practices of the firm.

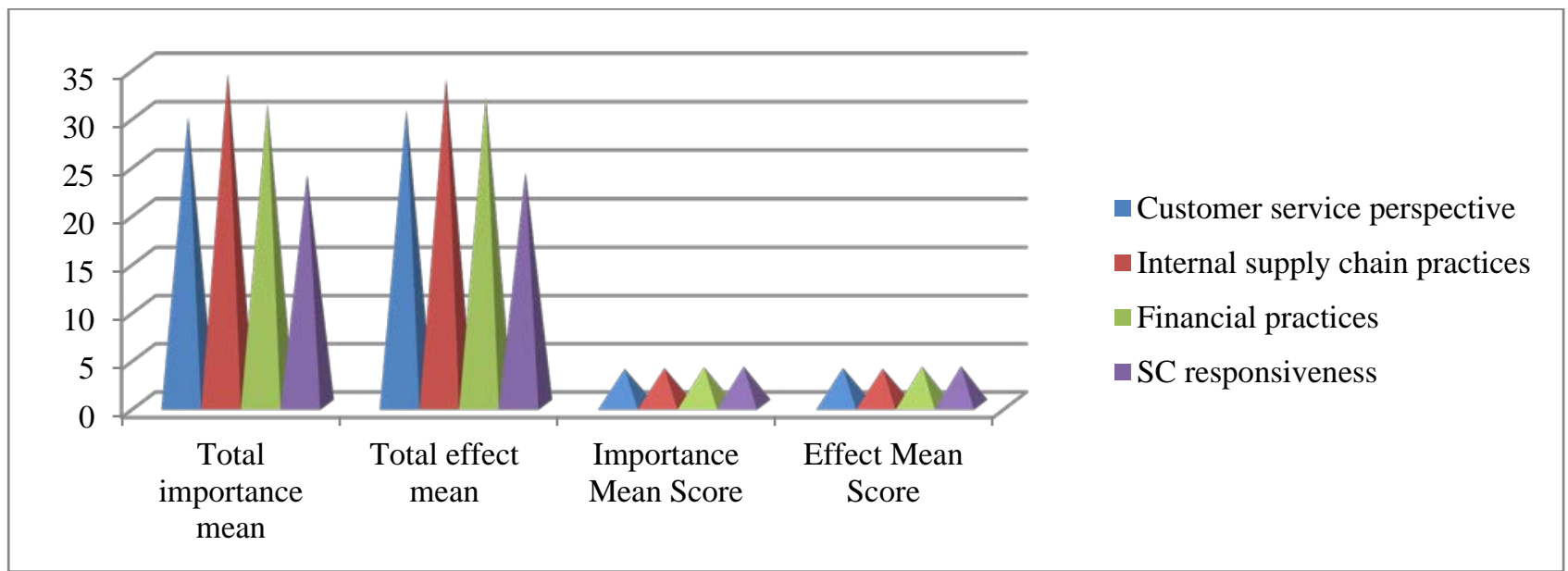

Fig. 10. Individual \& total importance and effect mean for SCP measures 
For the supply chain responsiveness measure had importance (3.96) and effect (4.00). Here the difference was only of the 0.04 score that was very low. The $\mathrm{P}$ value was 0.753 that expressed the both importance and effect mean having no significant difference. All the metrics score of importance and effect were between 3.64- 4.44 that were high and very good according to measurement scale. In farm product SC, SC responsiveness have immense importance. It need prompt delivery from all stages for reducing SC farm product wastage. Viswanandham (2005) demonstrated that the high share of farm product gets wasted due to lack of SC responsiveness. Olugu et al. (2011) also expressed that SC responsiveness has high importance in measuring SCP.

\section{Conclusion}

This investigation proposed 31-item Likert measurement scale with 4 measures for evaluating CSCP. A survey was conducted by distributing a questionnaire to farm products SC practitioner and academicians. The result infers that all 4 measures have important attributes and have an effect on CSCP. The organizations need to regular tab their SCP for making the CSP more effective and efficient to achieve firm's goal. Firstly, metrics for the measures were developed on the behalf of SC experts and academicians views. Then after the mean scores for all measures' metrics', importance and effect were calculated. The obtained mean score was represented through graphical presentations. It suggested that the product quality and product variety had some extent of difference between their importance and effect score. But there is no difference within the total measure scores. The statistical technique Mann-Whitney U-test was used to test the Null hypothesis (Ho = no significant difference between importance and effect mean of measures). The results of tests provided with the value more than 0.05 for all measures. This inferred that there was no significant difference between importance and effect mean score.

Only one limitation of this study refers to lacks the interrelationship among measures. The main purpose of this study was to develop SC measure and metrics and evaluation their importance and effect of SCP on farm product SC. But there is also another area in this industry where the research is needed. Today, the value addition in farm product is a key concept that can lead firms to capture untouched market size opportunities. So the future studies can employ the idea of evaluation of value addition in the each stage of farm product SC.

\section{References}

Amaeshi, K., Osuji, O. \& Nnodim, P. (2008). Corporate social responsibility in supply chains of global brands: a boundaryless responsibility? clarifications, exceptions and implications. Journal of Business Ethics, 81(1), 223-234.

Athapol, N., \& Ahmed, I. (2008). Food supply chain management and food safety: South \& east-Asia scenario. Agricultural Information Research, 17(4), 131-136.

Aramyan, L.H., Lansink, A.G.J.M.O., Vorst, J.G.A.J.V.D. \& Kooten, O.V. (2007). Performance measurement in agri-food supply chains: a case study. Supply Chain Management: An International Journal, 12(4), 304-15.

Aung, M.M. \& Chang,Y.S. (2014). Traceability in a food supply chain: Safety and quality perspectives. Food Control, 39, 172-184.

Brettel, M., Strese, S. \& Flatten, T.C. (2012). Improving the performance of business models with relationship marketing efforts - An entrepreneurial perspective. European Management Journal, 30 (2), 85-98.

Beamon. B.M. (1999). Measuring supply chain performance. International Journal of Operations and production, 19(3), 275-292.

Bhagwant, M. \& Sharma, M.K. (2007). Performance measurement of supply chain: A balance scorecard approach. Computer and Industrial Engineering, 53, 43-62. 
Bigliardi, B. \& Bottani, E. (2010). Performance measurement in the food supply chain: a balanced scorecard approach. Facilities, 28, 249-260.

Bogataj, M., \& Vodopivec, R. (2004). Stability of perishable goods in cold logistic chains. International Journal of Production and Economics, 93-94 (0925-5279), 345-356.

Bovea, M.D. \& Vidal, R. (2004). Increasing product value by integrating environmental impact, costs and customer valuation. Resources, Conservation and Recycling, 41(2), 133-145.

Bozer, Y.A. \& McGinnis, L.F. (1992). Kitting versus line stocking: A conceptual framework and a descriptive model. International Journal of Production Economics, 28(1), 1-19.

Bruckner, S., Albrecht, A., Petersen, B. \& Kreyenschmidt, J. (2013). A predictive shelf life model as a tool for the improvement of quality management in pork and poultry chains. Food Control, 29(2), 451-460.

Chan, F., Qi, H., Chan, H., Lau, H. \& Ip, R. (2003). A conceptual model of performance measurement for supply chains. Management Decision, 41(7), 635-42.

Chia, A., Goh, M. \& Hum S.H. (2009). Performance measurement in supply chain entities: balanced scorecard perspective. Benchmarking: International Journal, 16, 605-620.

Chowdhury, A., Karmakar, S., Reddy, S.M., Ghosh, S., \& Chakrabarti, D. (2014). Usability is more valuable predictor than product personality for product choice in human-product physical interaction. International Journal of Industrial Ergonomics, 44(5), 697-705.

Christopher, M. (1998). Logistic and supply chain management: strategies for reducing costs and improving services. In: Financial Times, $2^{\text {nd }}$ ed. Pitman Publishing, London.

Coltman, T., Bru, K., Perm-Ajchariyawong, N., Devinney, T.M. \& Benito, G.R.G. (2009). Supply chain contract evolution. European Management Journal, 27(6), 388-401.

Cox, A. \& Chicksand, D. (2005). The Limits of Lean Management Thinking: Multiple Retailers and Food and Farming Supply Chains. European Management Journal, 23(6), 648-662.

Datta, D.K. (2013). Industrial sickness in India - An empirical analysis. IIMB Management Review, 25 (2), 104-114.

Desmet, P.M.A., Nicolas, J.C.O. \& Schoormans, J.P. (2008). Product personality in physical interaction. Design Studies, 29(5), 458-477.

Dewi, I.A., Dania,W.A.P. \& Wardani, B.R.K. (2015). Supply chain performance identification of horticulture product at Cooperative Brenjonk in Trawas, Mojokerto. Agriculture and Agricultural Science Procedia, 3, 163-168.

Doyle, P. (1994). Setting business objectives and measuring performance. European Management Journal, 12(2), 123-132.

Elgazzar, S.H., Tipi, N.S., Hubbard, N.J. \& Leach, D.Z. (2012). Linking supply chains processes' performance to a company's financial strategic objectives. European Journal of Operational Research, 223(1), 276-289.

English, M., Castelluccia, M. \& Mynors, D.J. (2006). Eco-efficiency of the cold roll formed product supply chain, Journal of Materials Processing Technology, 177(1-3), 626-629.

Estampe, D., Lamouri, S., Paris, J. \& Brahim-Djelloul, S. (2013). A framework for analysing supply chain performance evaluation models. International Journal of Production Economics, 142(2), 247258.

Fan, X., Zhang, S., Wang, L., Y Yang, Y. \& Hapeshi, K. (2013). An evaluation model of supply chain performances using 5dbsc and lmbp neural network algorithm. Journal of Bionic Engineering, 10(3), 383-395.

Fatehpuria, S. (2013). Indian cold supply chain: A case study. International E-Journal of Ongoing Research in Management and IT, ISSN-2320-0065.

Fawcett, S.E., \& Cooper, M.B. (1998). Logistics performance measurement and customer success. Industrial Marketing Management. 27(4), 341-357.

Gunasekaran, A. \& Kobu, B. (2007). Performance measures and metrics in logistics and supply chain management: a review of recent literature (1995-2004) for research and application. International Journal of Production Research, 45(12), 2819-2840. 
Gunasekaran, A., Patel, C. \& McGaughey, R.E. (2004). A framework for supply chain performance measurement. International Journal of Production Economics, 87, 333-347.

Guritno, A.D., Fujianti, R. \& Kusumasari, D. (2015). Assessment of the supply chain factors and classification of inventory management in suppliers' level of fresh vegetables. Agriculture and Agricultural Science Procedia, 3, 51-55.

Handfield, R.B. \& Nichols, E.L. (1999). Introduction to supply chain management. Upper Saddle River, NJ: Prentice-Hall; 1999.

Holweg, M., Disney, S., Holmström, J. \& Smaros, J. (2005). Supply chain collaboration: making sense of the strategy continuum. European Management Journal, 23(2), 170-18.

Hunter, L. (2006). Low cost airlines: business model and employment relations. European Management Journal, 24(5), 315-321.

Jabbour, A.B.L.D.S, Filho, A.G.A., Viana, A.B.N. \& Jabbour, C.J.C. (2011). Factors affecting the adoption of supply chain management practices: Evidence from the Brazilian electro-electronic sector, IIMB Management Review, 23(4), 208-222.

James S.J. \& James C. (2010). Advances in the cold chain to improve food safety, food quality and the food supply chain. Delivering Performance in Food Supply Chain, Woodhead Publishing Series in Food Science, Technology and Nutrition, Chapter-18, 366-386.

Jile, F., Parton, K. \& Cox, R. (2007). Supply chain practices, supply chain performance indicators and competitive advantage of Australian beef enterprises: A conceptual study. Australian Agriculture and Resource Economic Society (AARES $1^{\text {st }}$ Conference).

Kale, J.R. \& Meneghetti, C. (2014). Supplier/customer considerations in corporate financial decisions. IIMB Management Review, 26(3), 146.

Karrer, M. (2003). Defining Supply Chain Performance. Kotzab, H. (ed.): Eighth ELA Doctorate Workshop 2003.

Khatri, N., Ojha,A.K., Budhwar, P., Srinivasan, V. Varma, A. (2012) .Management research in India: Current state and future directions. IIMB Management Review, 24(2), 104-115.

Lai, K., Ngai, E.W.T. \& Cheng, T.C.E. (2002). Measures for evaluating supply chain performance in transport logistics. Transportation Research Part E, 38, 439-456.

Lambert, D. \& Pohlen, T. (2001). Supply chain metrics. International Journal of Logistics Management, 12(1), 1-19.

Lan, H.J., Zhao, L., Su, L. \& Liu, Z.G. (2014). Food cold chain equilibrium based on collaborative replenishment, Journal of Applied Research and Technology, 12(2), 201-211.

Lee, H.L. (2000). Creating value through supply chain integration. Supply chain management Review. 4(4), 30-36.

Lee, H.L. \& Billington, C. (1992). Managing supply chain inventory: Pitfalls and opportunities. Sloan Management Review, 33(3), 65-73.

Lohman, C., Fortuin, L. \& Wouters, M. (2004). Designing a performance measurement system: a case study. European Journal of Operational Research, 156, 267-286.

Maheshwar, C., \& Chanakwa, T. S. (2006). Post harvest losses due to gaps in cold chain in India a solution. Acta Hort. (ISHS), 712, 777-784.

Mapes, J., New, C., Szwejczewski, M. (1997). Performance trade-offs in manufacturing plants. International Journal of Operations \& Production Management, 17(10), 1020-1033.

McKinnon, A. (1999). Vehicle utilisation and energy efficiency in the food supply chain. School of Management Heriot-Watt University Edinburgh, UK.

Mentezer, J.T. \& Konrad, B.P. (1991). An efficiency /effectivenss approach to logistic performance analysis. Journal of Business Logistic, 12 (1), 33-62.

Murthy, S. (2011). Market-implied risk-neutral probabilities, actual probabilities, credit risk and news. IIMB Management Review, 23(3), 140-150.

Najmi, A., Gholamian, M.R. \& Makui, A. (2013). Supply chain performance models: A literature review on approaches, techniques and criteria. Journal of Operation and Supply Chain Management, 6(2), 94-113. 
Neely, A., George, M. \& Platts, K. (1995). Performance measurement system design. International Journal of Operations \& Production Management, 10(5), 80-116.

Noone, B.M. (2008). Customer perceived control and the moderating effect of restaurant type on evaluations of restaurant employee performance. International Journal of Hospitality Management, 27(1), 23-29,

Park, J.H., Lee, J.K. \& Yoo, J.S. (2005). A framework for designing the balanced supply chain scorecard. European Journal of Information System, 14, 335-346.

Parraga, L.P., Gomez-Lobon, A., Runnenberg, I.G., Melantuche, R.S., Sanchez, O.D. \& Latorre, F.P. (2011). Thermolabile Drugs. Operating Procedure in the Event of Cold Chain Failure, Farmacia Hospitalaria, 35(4), 190.e1-190.e28.

Persson, F. \& Olhager, J. (2002). Performance simulation of supply chain designs. International Journal of Production Economics, 77(3), 231-245.

Porter, M.E. (1985). Competitive advantage: creating and sustaining superior performance. Free Press, New York.

Qin, L. (2010). An effective way to improve the performance of food safety governance based on cooperative game. Agriculture and Agricultural Science Procedia, 1, 423-428.

Ramdas, K., \& Sperkman, R.E. (2000). Understanding what driver supply chain performance. Interface, 30(4), 3-21.

Rani, N. Yadav, S.S. \& Jain, P.K. (2015). Market response to the internationalization strategies: Evidence from Indian cross-border acquisitions. IIMB Management Review, Available online 21 April 2015, ISSN 0970-3896.

Ren, Y. \& An, Y. (2010). Efficient food safety regulation in the agro-food wholesale market. Agriculture and Agricultural Science Procedia, 1, 344-353.

Reed, A.M. \& Reed, D. (2010). Business and development. IIMB Management Review, 22(3), 111127.

Schroeder, R.G., John, C.A. \& Scudder, G.D. (1986). White collar productivity measurement. Management Decision, 24(5), 3-7.

Shabani, A., Saen, R.F. \& Torabipour, S.M.R. (2012). A new benchmarking approach in cold chain, Applied Mathematical Modelling, 36(1), 212-224.

Shah, J., Singh, N. (2001). Benchmarking internal supply chain performance: development of framework. The Journal of Supply Chain Management, 37(1), 37-47.

Shashi, S. \& Singh, R. (2015). Modeling cold supply chain environment of organized farm products retailing in India. Uncertain Supply Chain Management, 3(3), 197-212.

Singh, R., Sandhu, H.S., Metri, B.A \& Kaur, R. (2013). Modeling Supply Chain Performance: A Structural Equation Approach. International Journal of Information Systems and Supply Chain Management, 6(4), 18-41.

Singh, R., Sandhu, H.S., Metri, B.A \& Kaur, R. (2014). Supply Chain Management Practices, Competitive Advantage and Organizational Performance: A Confirmatory Factor Model. International Journal of Information Systems and Supply Chain Management, 7(2), 22-46.

Stewart, G. (1995). Supply chain performance benchmarking study reveals keys to supply chain excellence. Logistics Information Management, 8(2), 38-44.

Thomas, D.J. \& Griffin, P.M. (1996). Co-ordinated supply chain management. European Journal of Operational Research, 94(3), 1-15.

Turker, D. \& Altuntas, C. (2014). Sustainable supply chain management in the fast fashion industry: An analysis of corporate reports. European Management Journal, 32(5), 837-849.

Varma, S., Wadhwa, S. \& Deshmukh, S.G. (2008). Evaluating petroleum supply chain performance. Asia Pacific Journal of Marketing Logistic, 20, 343-356.

Viswanadham, N. (2006). 1 Can India be the Food Basket for the World?. Achieving Rural \& Global Supply Chain Excellence, 1.

Wong, W.P. and Wong, K.Y. (2007). Supply chain performance measurement system using DEA modeling. Industrial Management \& Data Systems, 107(3), 361-381. 
Xu, J., Li, B., \& Wu, D. (2009). Rough data envelopment analysis and its application to supply chain performance evaluation. International Journal of Production Economics, 122, 628-638.

Zhao, R., Qiao, J. \& Chen, Y. (2010). Influencing factors of consumer willingness-to-buy traceable foods: An analysis of survey data from two Chinese cities. Agriculture and Agricultural Science Procedia, 1, 334-343.

Zorzini, M., Stevenson, M. \& Hendry, L.C. (2012). Customer Enquiry Management in global supply chains: A comparative multi-case study analysis. European Management Journal, 30(2), 121-140. 